ing it by one stitch at the mesenteric border. Lateral anastomosis may be done in substantially the same manner.

The advantages of the method are: 1 , the approximator will quickly disappear and will therefore give no future anxiety; 2, with the approximator in place the mesentery may be accurately adjusted by rotating before suturing; 3 , the ease and rapidity with which the union can be effected (Specimen 8 shows one removed from a dog upon which $I$ operated without assistance); 4, the ease, rapidity and cheapness of manufacture of the approximator; 5 , the spiral catgut stitch uniting the edges of the coats, tends to prevent accumulation of fluid and formation of abscess beneath the mucous coat; 6 , a doctor of average surgical ability can perform the operation when emergency demands.

$$
\text { DISCUSSION. }
$$

Dr, H. H. Grant of Louisville-I have done several of these operation both anatomically and surgically, and have gotten along as well without artificial aid as with it. The device sug gested is a slight modification of the one we are familiar with merely using a potato or turnip and preparing it just before the operation. The device facilitates the operation in the hands of those who have had little experience in the handling of the needle but the time occupied is not much less than a skilled operator would employ without much aid. If we must use a mechanical device we should employ the Murphy button. It is true that failure has occasionally resulted from imperfect approximation of the surfaces with the Murphy button, but this results largely from a want of familiarity with the mechanism of the button. If the serous surfaces are brought accurately together, the necessity for the use of sutures will rarely occur. The employment of these devices takes time and adds to the risk of hemorrhage. There is very little to do in securing apposition of the surfaces other than that which nature will take care of, and I question whether it will be to the inter est of the profession to substitute anything for the Murphy button which can usually be dispensed with.

Dr. Metcalf, in closing: I agree with the gentleman who has discussed my paper that it is an easy thing to do an intestinal anastomosis, but it is not easy at times to make the anastomoses that we are called upon to do. My experience is that I can do the operation in one-half the time that I used to be able to do it, and in such a way that there will be less serous surface to approximate. The results will be more accurate and the subsequent contraction less.'

\section{THE ADVANTAGES OF A PERMANENT} ABDOMINAL ANUS AND OF TOTAL CLOSURE OF THE SACRAL END OF THE RECTUM, IN OPERATIONS FOR CANCER OF THE RECTUM.

Presented to the Section of Surgery and Anatomy at the Forty-ninth Annual Meeting of the American Medical Association, held at Denver, Colo., June 7-10, 1898. BY W. W. KEEN, M.D.

PROF. PRINCIPLES OF SURGERY AND OF CLINICAL SURGERT, JEFFERSON MEDICAL COLLEGE, PHILADELPHIA.

In the Therapeutic Gazette for May, 1897, I published fifteen cases of amputation of the rectum by Kraske's method, to which I have since added two more, making seventeen in all. Three of the patients died, giving a mortality of 17.07 per cent. Of the fourteen cases that have recovered, six have now passed beyond the three-year limit and may be considered reasonably safe from recurrence. Two of the men, in spite of the loss of the coccyx and part of the sacrum, ride bicycles with ease. Besides these the paper included a number of other cases of cancer of the rectum, operated on by other methods.

As a result of my experience in these cases, I have reached a definite conclusion as to what is the best course to pursue. Evidently after the operation the bowel must continue to be emptied of its contents. There are only three ways in which this can be done. First, in those rather rare cases in which the sphincter can be preserved and the lower end of the bowel sutured to the upper, $i$. e., a resection rather than an amputation of the rectum we restore the natural function of the bowel through the normal anus. Second, if the anus and sphincter have had to be removed, we can suture the sacral end of the rectum at the end of the resected sacrum, pass it through the gluteal fibers and make an artificial sphincter, or rotate it to such an extent as to make a sort of supplementary sphincter. I have not tried bringing the end of the rectum out through the fibers of the gluteus maximus muscle. Both of the other methods I have tried, but

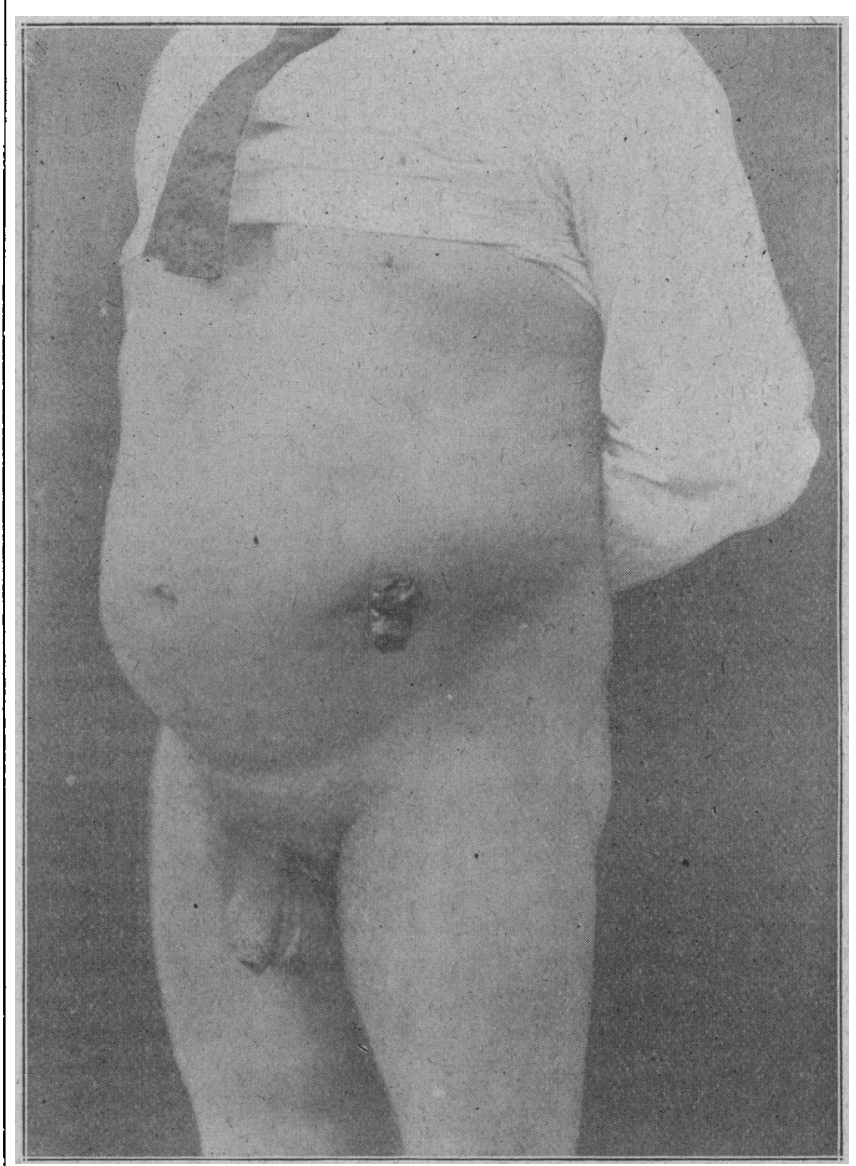

Figure 1.-The inguinal anus in Case 1.

neither has proved satisfactory. Rotation of the bowel has been followed by infection in the folds of the rectum and not very satisfactory results as to retention of feces. The sacral anus has not been satisfactory, first because it necessitates the patient's wearing for the remainder of his life, day and night, a napkin, partly on account of the constant escape of mucus, and partly on account of the want of control of the feces. In addition to this, there has always followed a greater or less prolapse of the bowel, which in some cases even reached six inches. No perineal napkin can be worn tight enough to produce pressure sufficient to prevent either of these annoyances.

Besides the annoyance of wearing a napkin, the involuntary escape of mucus and feces and prolapse of the bowel, the sacral anus has another danger at 
the time of operation and afierward, namely, infection of the wound. This infection is due partly to the fact that the bowel can not be suitably evacuated, nor can it be disinfected before the operation by means of the natural anus. The cancer forms such an obstruction that neither can the feces escape downward, nor can satisfactory cleansing of the bowel be accomplished by means of enemata. After the operation also the danger of infection from the escaping feces is a constant menace to the success of the operation. I have therefore in my later operations always made a preliminary colostomy by Maydl's method. At the end of about a week, I have excised all of the protruding portion of the bowel, leaving a permanent artificial anus. The advantages of this are, first, that before the operation one can empty the upper bowel completely, and disinfect the lower bowel partly through the natural and partly through the artificial

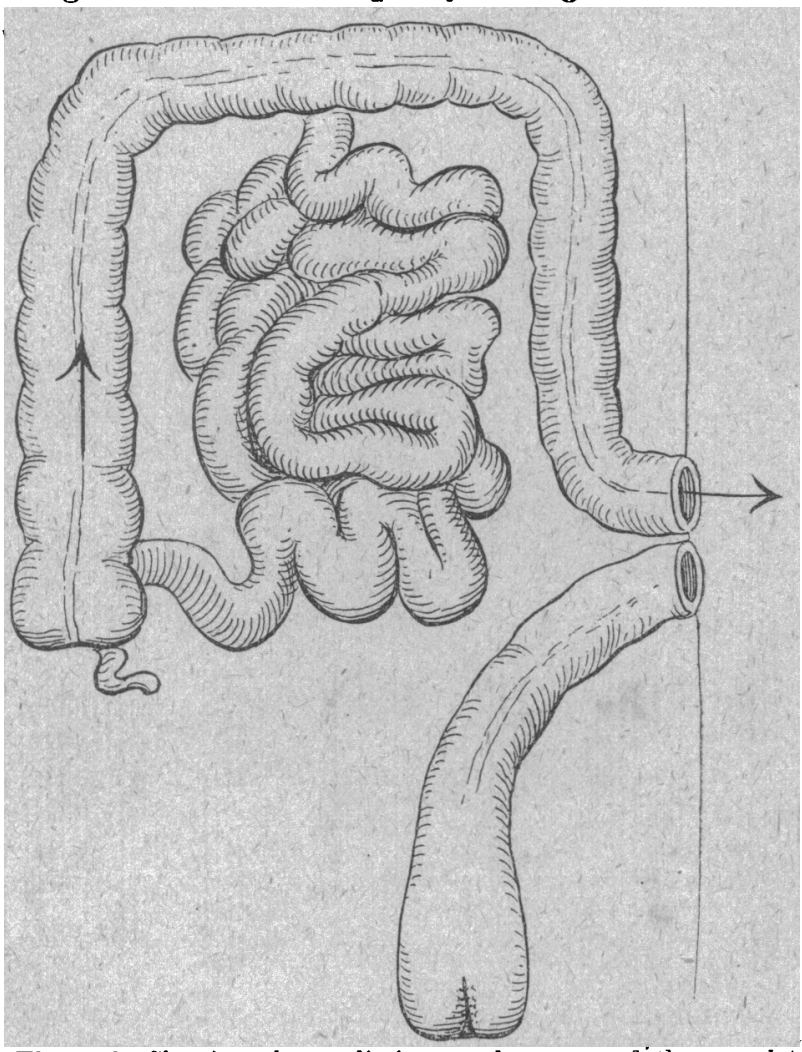

Figure 2.-Showing the preliminary colostomy and the complete closure of the sacral end of the rectum after amputation.

anus. In the paper already alluded to, I have shown the impossibility of disinfecting or even of unloading the bowel prior to amputation of the rectum, even after days or weeks of effort. Secondly, an abdominal artificial anus is very much more under control, and can be cleansed very much better than a sacral anus. One can wear a belt or girdle as tight as is necessary, both to prevent undue protrusion and to prevent the escape of the feces. Figure 1 shows the result in one of my recent cases. Prolapse is present to a slight degree, but does not annoy the patient. $\mathrm{H}_{\Theta}$ is a blacksmith and does his work perfectly well. Most of the cases with such an artificial anus have the bowel emptied spontaneously, once, or more commonly twice, a day, and at almost as regular hours as by the normal rectum. Of course when there is diarrhea no control over the evacuation remains, but as I have shown in my previous paper, by means of a suitable dressing, the contents of the colon, as they escape, are caught and are prevented from becoming a source of annoyance to the patient or those about him.

In the last two cases upon which I have operated, I have taken a further step which $I$ think is a distinct improvement in rectal surgery, namely: after amputation of the rectum, I have completely closed the sacral end of the rectum, just as one closes the end of the intestine before making a lateral anastomosis (Figure 2). The first advantage of this is that if the closure is a success, neither fecal matter nor infected mucus can reach the wound, and we are much more likely to obtain primary union, which greatly lessens the danger of life. Secondly, as the perineal wound is entirely closed, no escape of either feces or mucus occurs after recovery and the patient is relieved of the necessity of wearing a napkin. Thirdly, for the same I

I have carried out this plan in two cases. I was not able to avoid infection, because in the first cases there was slight leakage, and in the second there was an unavoidable dead space left at the end of the

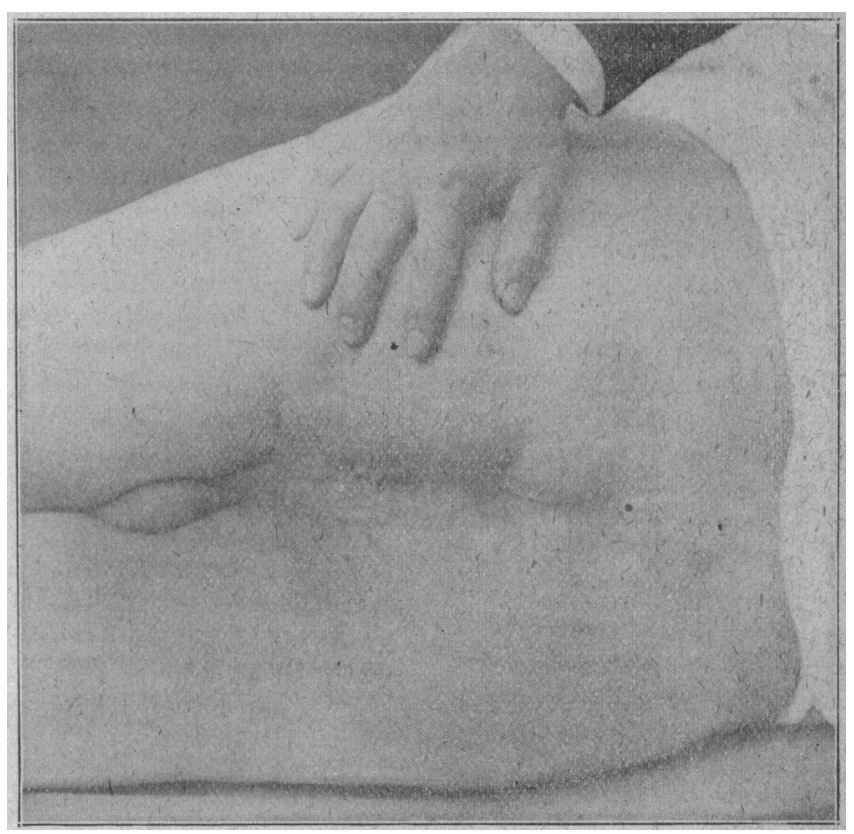

Figure 3.-Complete closure of the perineum without any sacral anus after amputation of the rectum.

sacrum, and a slight Feactionary hemorrhage. But both of these cases suffered far less from febrile reaction than I have seen after the more severe infection by ordinary methods; and both have made excellent recoveries. The second case is too recent to express an opinion as to the functional results. These, in the first case, could not be better. Seven months have passed since this operation and his physician, Dr. Bashore of Bachmansville, $\mathrm{Pa}$., has recently written me that the patient is working hard at his trade as a blacksmith, and can shoe as many as six horses in a day. When one remembers that in shoeing horses a blacksmith bends far over and almost constantly, one can see the great advantage that this man has in being free from the discharge and the prolapse of a sacral anus, and the necessity of wearing a napkin. Figure 3 shows the present condition of his perineum.

I would like also to call attention to the ease with which in case 2 the upper and lower colon were exam- 
ined by Kelly's tube from the artificial anus as far as the sigmoid and the transverse colon. In doubtful cases, as this was, the method will prove of great use in determining whether any operation should be done.

\section{A brief account of these cases is as follows:}

Case 1. - Mr. H. H., age 55. Has had bloody passages from the rectum for three years, and has lost 29 pounds in weight, although still weighing $175 \mathrm{lbs}$. A thick, nodular mass entirely surrounds the rectum; no adhesions. Nov. 3, 1897, preliminary colostomy, Maydl's method. Bowel opened on second day, and entire protruding portion cut off flush with the abdominal wall at the end of a week. Disinfection of the lower bowel by boric acid through the natural and the artificial anus. Nov. 17, resection of rectum and coccyx, and sacrum removed to $3 \mathrm{rd}$ sacral foramen; $13 \mathrm{~cm}$. (5 in.) of the bowel amputated, without opening the peritoneum, but exposing the prostate, vesiculæ seminales, and a large part of posterior wall of bladder (Fig. 4). Fifty ligatures. Invagination and closure by Lembert sutures of lower end of rectum. Closure of perineal wound. On the fifth day, probably as a result of slight leakage, temperature 103 degrees. Small amount of pus evacuated, when temperature immediately fell. Out of bed on 18 th day, and went home a few days after. Dr.

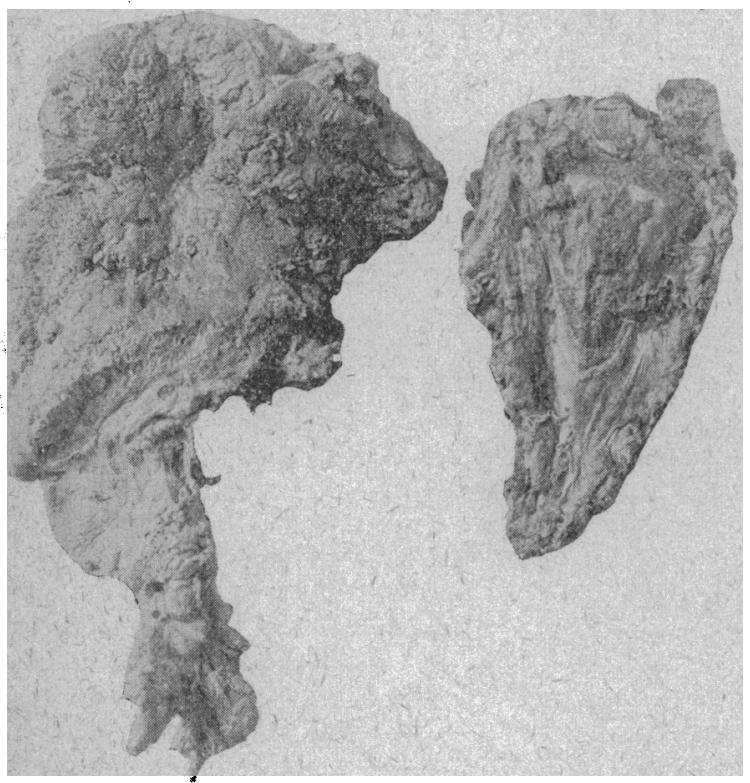

Figure 4.--Specimens removed in Case 1. Rectum, coccyx and part of sacrum.

Bashore writes: "The artificial anus answers admirably and has no disadvantages whatever. The mucus that collects in the rectum and lower colon is expelled upward. In the patient's own words: 'I feel as I formerly felt before stool; then, on bending forward, a sensation as if I had a stool, and the mucus is expelled on the bandage.' This happens about once in two days. He is in splendid physical health and has resumed active work as a blacksmith."

Case 2.-E. T., age 50. Pain in the rectum for a year and a half, with occasional blood. Was admitted to the Jefferson Hospital Dec. 20,1897. A week before his admission I had examined the rectum in the out-patient department, by Kelly's proctoscopic tubes, and found a number of small polypi. Three of these were twisted off and examined by Prof. Coplin, who reported that they were tubulated adenomata, which in a patient of his age usually developed rapidly into cylindrical carcinomata. Dec. 22, 1897, I re-examined the rectum with the patient in the knee chest position and found a larger number of even larger growthe than were discovered at the first examination. The larger ones were sessile. As it was evident that it would not be possible completely to extirpate these growths, and in view of their probable development into carci nomata, I advised amputation of the rectum.

Operation, March 19, 1898. Colostomy by Maydl's method. After packing the colon with iodoform gauze, I opened it immediately in the long axis and inserted Kelley's proctoscope, $22 \mathrm{~mm}$. in diameter, $9 \mathrm{~cm}$. downward and $8 \mathrm{~cm}$. upward from the colostomy wound. I therefore was able to examine the rectum into the sigmoid flexure and into the transverse colon. Had I found that the adenomata extended upward into the colon to any great distance, I should have closed the bowel and abandoned further operation. As nothing abnormal was seen in either direction I decided la ter to amputate the rectum. The wound in the colon was therefore closed with glover sutures temporarily and was permanently opened at the end of a week.

Rectal operation, A pril 6, 1898. The ordinary Kraske operation was done, the sacrum being divided at the level of the third foramen. The prostate urethra and bulb of the corpus songiosum and a portion of the wall of the bladder were exposed. Thirteen $\mathrm{cm}$. of the rectum were removed (Fig. 5). A small rent was made in the peritoneum, but was immediately sewed up. Immediately above the growth the rectum narrowed very sharply to a calibre scarcely larger than the forefinger. Owing to the height and small size of the rectum, there was great difficulty in invaginating the lower end. At the end of the sacrum it was not possible to draw the soft parts together, and in consequence a considerable dead space was left, which I packed with iodoform gauze. A certain amount of reactionary hemorrhage took place that night, which required several sutures to be cut and a repacking with gauze. The day after the operation his temperature was 101.8 but on

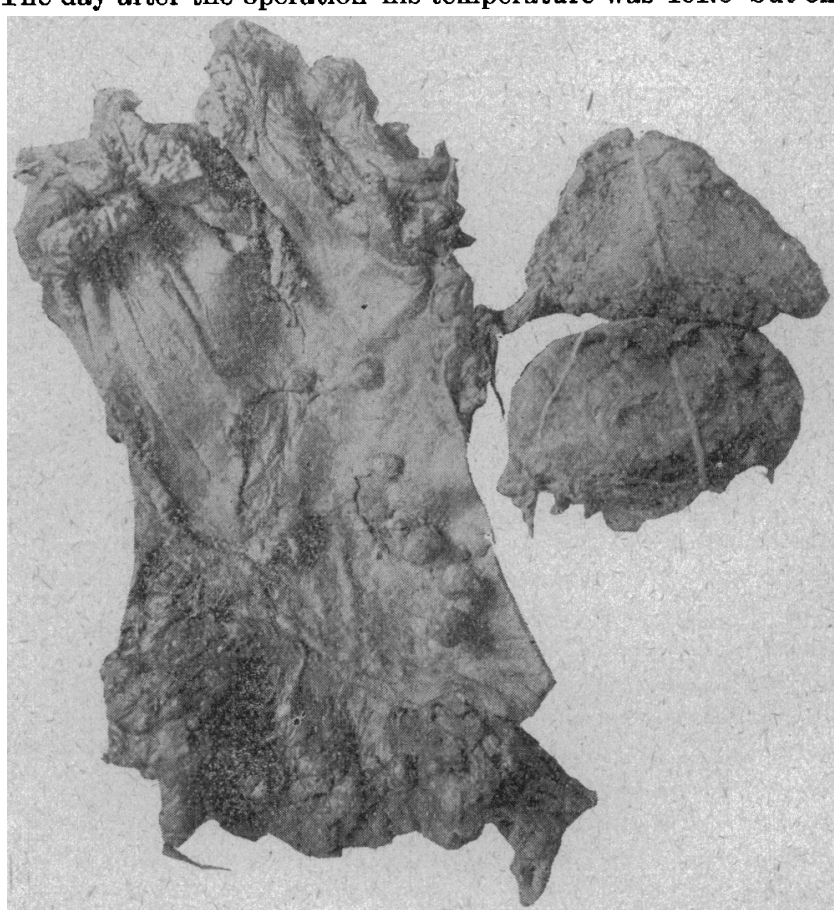

Firure 5,-Specimens removed in Case 2. Rectum and coccyx and part of sacrum, removed in two pieces.

the second day had fallen to 99 degrees. From then until the tenth day it fluctuated between normal and 100 degrees, but after that was entirely normal. The dead space left had slowly filled up, but was not quite cicatrized when he left the hospital, early in June. Since then it has entirely closed and he is in excellent health.

\section{THE MEDICAL ASPECTS OF APPENDICITIS.}

Presented to the Section on Surgery and Anatomy at the Forty-ninth

Annual Meeting of the American Medical Association, held at Denver, Colo., June, T-10, 1898.

BY H. A. HARE, M.D.

PHILADELPHIA, PA.

In reading this paper on the medical aspects of appendicitis I am well aware that in view of the beliefs of some surgeons I am ordered to lead a hopeless cause. I hope to show, however, that this is not the case, although it is necessary for us to arrive at a definite idea as to what this title means. If it refers to the medical treatment in distinction to the surgical treatment and in the sense of the use of medicines in place of operative interference, then $I$ am the wrong one to have asked to write on it, not that I believe that all cases are operative, but because I believe some are and some are not. If the diagnosis of the appendicitis is at issue cther lines of experience must 